\title{
Mood and Food Cravings in Overweight and Obese Australian Adults: Clues to Treatment in Food Diaries
}

\author{
Peta Stapleton and Wava Doyle \\ Department of Psychology, Faculty of Humanities and Social Sciences, \\ Bond University, Gold Coast, Queensland, 4229, Australia
}

Received 2013-10-10, Revised 2013-11-02; Accepted 2013-11-02

\begin{abstract}
The objective of this study was to examine food diaries from 89 female overweight and obese adults participating in a treatment trial for food cravings. For two weeks prior to beginning treatment and for the duration of the four-week treatment, all participants were required to complete a daily food monitoring sheet or diary in real-time, indicating all quantities of food/drink eaten throughout a day and whether the item was a craving item for them. The diaries were examined for narrative statements and categorized with regard to common content, resulting in seven themes (Physiological; Enjoyment/Celebration; Missing Out; Reward; Wastage; Emotive and External Environment). Participants also completed a battery of self-report questionnaires relating to food cravings, eating behaviour and psychological symptoms. Results indicated that the most common themes recorded included Wastage, Emotive and Reward and the most frequent number of cravings recorded per day ranged from one to three.
\end{abstract}

Keywords: Mood, Food, Obesity, Adults, Diary, Cravings

\section{INTRODUCTION}

While Australians are generally 'healthy' and currently enjoy one of the highest life expectancies in the world -79.5 years for men and 84.0 years for women (ABS, 2012), the prevalence of overweight and obesity in adults aged 18 years and over has continued to rise to $63.4 \%$ in $2011-12$ from $61.2 \%$ in $2007-08$ and $56.3 \%$ in 1995 (ABS, 2012). This equates to approximately 18 million adults. Between 1995 and $2011-12$, the $7.1 \%$ increase resulted in approximately 1.28 million extra adults becoming overweight or obese (ABS, 2012). This now places Australia with more than one in four adults being obese. Furthermore, the increasing rate of overweight and obese adults in Australia appears to be on par with the rest of the world; Australian men having the second highest rate of obesity among Organisation for Economic Cooperation and Development (OECD) countries and women ranking a close fifth (ABS, 2012). This recent increase in statistics has resulted in the Australian Government setting one of its health priorities to halt and reverse current obesity trends.

There is little doubt as to the physical effects of being overweight or obese. Obesity increases cardiovascular disease risk factors, type 2 diabetes and overall mortality (Fujioka, 2012; NHMRC, 2013). It is also commonly associated with poverty (James et al., 2012). The costs of being obese extend into areas previously attributed to protracted and enduring health conditions and now include employment absenteeism, disability, workers' compensation costs and premature mortality (Trogdon et al., 2008). The cost of obesity to Australia's collective wellbeing has reached $\$ 120$ billion a year: the equivalent of $8 \%$ of the economy's annual output (LE, 2011). Psychosocial problems including eating disorders, depression (NHMRC, 2013) Gold Coast, Queensland, 4229, Australia Tel: +61 755952515 Fax: +61 755952540 
and stigmatization because of weight issues also means obese individuals face various forms of prejudice and discrimination (Sechrist et al., 2005; Teachman et al., 2005).

Current approaches to addressing this epidemic have included combined dietary and physical activity approaches (McGuire et al., 1999; Wing and Hill, 2001; Wing and Phelan, 2005) and of late, behavioural strategies including motivation to influence the weight loss process (Bandura, 1986; NHMRC, 2013; Prochaska et al., 1992). However, weight loss and maintenance appear complex issues and research suggests dieting regularly results in weight loss in the short term (Perri and Fuller, 1995), but meta-analysis indicates that the more time that elapses between the end of a diet and the follow-up period, the more weight is regained (Mann et al., 2007). Short term studies of weight loss do not often indicate the benefits on healthrelated outcomes and also do not address what occurs when weight is regained (Mann et al., 2007). Indeed, weight cycling has been associated with decreased perceptions of health and well-being (Foster et al., 2012), excess body weight and abdominal fat accumulation (Cereda et al., 2011).

The area of successful weight maintenance is new and under-researched. Similar to many therapeutic models, treatment characteristics, such as continued therapist contact, have been shown to increase the likelihood of weight maintenance (Perri et al., 1989). More frequent contact with a healthcare professional is generally more successful in the short term (NHMRC, 2013). A review of the largest observational study examining weight loss maintainers of more than a year, the National Weight Control Registry (Hill et al., 2005; Raynor et al., 2012; Wing and Hill, 2001), highlighted that to be successful at weight loss maintenance over time, individuals must have limited variety in food groups and consume a low-energy diet as well as dedicate to a consistent exercise regimen (McGuire et al., 1999). The themes present in the weight maintenance literature appears to be that behavioral control, self-control and willpower are required to maintain restricted food choices and engage in frequent and strenuous physical activity. However it has been noted that willpower relies on the same cognitive process as decision making and may be a limited resource that leads to reversion in eating behaviour (Baumeister and Vohs, 2003).

While it appears that the addition of these behavioral strategies result in longer weight loss maintenance over time, it seems there may be a missing link in the weight loss/obesity field. This relates to recognizing the complex psychological factors involved and, therefore, the need for comprehensive psychological treatment in conjunction with physical and dietary approaches. A recent study investigating the psychological, cultural and social contributions to overeating in obese people (Grant et al., 2008) found that eating for comfort for the morbidly obese is rooted in using food to manage experiences of emotional pain and difficult family and social relationships. Participants reported that what had been missing from all treatment programs they had tried was the opportunity to work on the psychological issues concurrently with weight loss (Grant et al., 2008).

The addition of psychological techniques to existing weight loss programs indicate that people who are overweight or obese do benefit from psychological interventions (Shaw et al., 2005). A Cochrane review (Shaw et al., 2005) highlighted that Cognitive Behaviour Therapy (CBT) and Behaviour Therapy (BT) significantly improved the success of weight loss for overweight and obese people. Cognitive therapy alone though, was not found to be effective as a weight loss treatment. The evidence available for other strategies, such as relaxation therapy and hypnotherapy, also indicated that these may be beneficial in improving weight loss (Shaw et al., 2005).

To improve standard behavioral weight loss interventions, this study sought to elicit the subjective views of participants involved in a food craving treatment program (Stapleton et al., 2011; 2012b), prior to and throughout their group intervention. Our interest was in their perceptions and beliefs about their food cravings, emotions associated with food and eating behaviour and their resultant behaviour. The reason for the qualitative approach was to allow us to examine information, which might otherwise go unreported, but may be of clinical use in treatment programs. The value of qualitative methods in researching participant attitudes is well recognized (Fitzpatrick and Boulton, 1994). Previous research has suggested more food records or diaries kept per week by a participant may be a significant predictor of attendance and adherence to a weight loss program and actual weight loss (Hollis et al., 2008). In fact, in Hollis et al. (2008) randomized trial comparing alternative strategies for maintaining weight loss over a 30 -month period, the author found that diet records and physical activity accounted for the most weight loss variation across race and gender groups. 


\section{MATERIALS AND METHODS}

\subsection{Participants}

Eighty-nine overweight and obese adults were involved in a brief weight loss intervention focusing on food cravings over a four-week period. The participants attended two hours of treatment per week and were randomly allocated to one of two groups: Emotional Freedom Techniques (EFT) or a Waitlist (WL). Ethics approval was obtained from the lead author's affiliated university (Griffith University at the time). Weight status was determined through the internationally accepted standardized classification of overweight and obese, based on the Body Mass Index (BMI), which is a weightto-height ratio, calculated by dividing one's weight in kilograms by the square of one's height in meters (RWHOC, 2000). Obesity is defined as a BMI above 30 $\mathrm{kg} \mathrm{m}^{-2}$, while overweight is defined as a BMI above 25 $\mathrm{kg} \mathrm{m}^{-2}$. Morbid obesity occurs at a BMI above $40 \mathrm{~kg} \mathrm{~m}^{-2}$ (RWHOC, 2000).

All participants in the EFT group were asked to complete a questionnaire package and were weighed and had height recorded pre-test (at recruitment, before treatment) and post-test (immediately after treatment). At the end of the four-week treatment condition, the WL participants were then offered the group treatment. The WL condition were weighed, had their height taken and completed a questionnaire package pre-test (at recruitment, on entry to the WL), post-test/pre-treatment (after the WL test period, at the beginning of the WL treatment) and post-treatment (immediately after the WL treatment).

\subsection{Participants}

All 89 voluntary participants in this part of the study were female and aged between 31 and 56 years (the majority of women were in the 41-56+ year age bracket; $\mathrm{N}$ $=30,34 \%$ ). Mean weight of the group was 69.78 kilograms $(\mathrm{SD}=42.93)$ and mean BMI was $34.28(\mathrm{SD}=6.93)$. Fortythree participants were in the overweight range according to BMI guidelines and 46 were classified as obese. Of these 46, 10 were morbidly obese (11\%).

\subsection{Measures}

All eligible participants were asked to complete a demographic questionnaire. In addition, they completed the Food Craving Inventory (FCI) (White et al., 2002), which is a reliable and valid measure for the assessment of cravings for specific types of foods, namely: High Fats, Sweets, Carbohydrates/Starches and Fast Food Fats, all of which comprise the higher order construct of "food craving" or the FCI Total score (White and Grilo, 2005). Higher numbers for each of the subscales reflect greater cravings for that food type with the highest score being 185 .

The Power of Food Scale (Lowe et al., 2009) was used and is a 21-item scale designed to assess the psychological influence of the mere presence or availability of food. It measures appetite for, rather than consumption of, palatable foods. The authors suggest that the POF may tap a pre-existing tendency toward heightened appetitive responses to food that could contribute to the development of obesity and some forms of disordered eating. Higher scores indicate a greater responsiveness to the food environment.

Three aspects of eating behaviour (cognitive restraint, uncontrolled eating and emotional eating) in the Revised Restraint Scale (Herman and Polivy, 1980; Polivy et al., 1988) were measured because the eating behaviour of low restraint people seems to conform to the pattern that typically characterizes 'normal' weight individuals, namely, "internal" regulation of food intake. In comparison, people with high restraint have more "external" regulation and the presence of food cues, once restraint has been abandoned, serves to trigger additional eating. Scores range from zero to four, with a total of 40 and high scores indicate chronic dieting (Herman and Polivy, 1980; Polivy et al., 1988).

Finally, the Symptom Assessment 45 (SA-45) was used to measure symptomology across nine psychiatric domains (SAI, 1998) namely: anxiety, depression, obsessive-compulsive, somatization, phobic anxiety, hostility, interpersonal sensitivity, paranoid ideation and psychoticism. It is a short-form of the Symptom Checklist (SCL-90) and also results in a Positive Symptom Index (PST), used toindicate the total number of symptoms reported to be present (i.e., item yielding a response other than "Not at all") and a Global Severity Index (GSI), which represents the total of the item response values for all items on the SA-45. Each of the nine symptoms is evaluated on a scale of 0 to 4 , with a total of 45 items having Likert-type response options $(0=$ nothing; $1=$ little; $2=$ moderate; $3=$ more; and $4=$ most).

\subsection{Treatment Condition}

The treatment condition (EFT) was offered in groups of 15 participants and was conducted by a 
qualified EFT practitioner. Each session was offered once a week for two hours, for a total of four weeks. The specific session topics were: (1) Psycho-education about EFT and how it works; (2) The nature of food cravings and how they can be addressed with EFT; (3) Feelings and Food; and (4) Relapse prevention using EFT for stress and relaxation and goal setting.

\subsubsection{Emotional Freedom Techniques}

Often referred to as "psychological acupuncture", these procedures (e.g., EFT) combine cognitive strategies with somatic procedures adapted from acupuncture and related systems for altering the cognitive, behavioral and neurochemical foundations of psychological problems (Craig, 2011; Flint et al., 2005). EFT contains elements of both exposure and cognitive therapy, but, to these established methods, adds the novel element of somatic stimulation. It has been found to have physiological mechanisms consistent with a lowering of the stress response and a calming of the threat-assessment structures in the midbrain. These include a reduction in the body's secretion of stress hormones, such as cortisol, an increase in endogenous opioids and a dampening of fear in the amygdala (Church et al., 2012; Feinstein, 2012).

\subsection{Food Diary}

For two weeks prior to beginning the treatment condition and for the duration of the four-week program, all participants were required to complete a daily food monitoring sheet or diary in real-time, indicating all quantities of food/drink eaten throughout a day and whether the item was a craving item for them. The definition of a craving was "an intense desire to consume a particular food (or food type) that is difficult to resist" (White et al., 2002). This was rated using a 7-point Subjective Units of Distress Scale or SUDS (Wolpe, 1990). Relevant antecedents (cognitions and emotions) and environment were also noted. Food diaries were chosen as a method that best measures real-life eating behaviour and as a behavioral strategy, have been linked to successful weight loss (Wadden et al., 2004).

\section{RESULTS}

\subsection{Qualitative Analysis}

The method of analysis involved examining narrative statements in the diaries and categorising them with regard to common content (Tesch, 1990; Weber, 1990). This is a common qualitative approach and allows the researcher to make comparisons (Miles and Huberman, 1984). Rather than defining categories first, the lead author inspecting the data in the current study, allowed categories to emerge. It has been suggested this is a more accurate reflection of the content (Dey, 1993). The emergent themes were then coded and care was taken to ensure the codes accurately captured the participant's meaning. The result themes were:

- Physiological-indicated by participants recording they were eating in response only to "hunger"

- Enjoyment/Celebration-indicated by participants recording they were eating because of a celebration. An example was "looking forward to going out with family

- Missing Out- participants indicated they were eating because of a fear of missing out: "could not resist" and "needed to finish my friend's hot chips

- Reward-this common theme was indicated through responses such as "I didn't have a chocolate this morning" and "just got home from work and deserved it"

- Wastage- any reason for eating relating to discarding food. Examples include "I couldn't waste it" and "there were left overs"

- Emotive-any emotion which appeared to be the cause of the food eaten was coded as emotive reasons. Examples included "bored" and "felt bad"

- External environment-any situation which did not appear to be coded through the previous themes and were related to the external environment were noted here. These were typical of the presence of food in the environment. Examples included "cake on table in meeting"

Inspection of the variable means for the quantitative measures (Table 1) indicated that all measured forms of restraint and an individual's power over food were above the midpoint of the scales. Inspection of the variable means for the food craving scale were below the midpoint of the scale, however, it does not have a defined cut-off severity score, instead increasing scores indicate more food cravings. Overall, the sample appeared to have concerns with food cravings, limited restraint ability and a tendency toward heightened appetitive responses to food. 
Peta Stapleton and Wava Doyle / Current Research in Psychology 4 (1): 6-15, 2013

Table 1. Means, Standard Deviations at Pre, Post, 6-months and 12-months for Collapsed Groups

\begin{tabular}{|c|c|c|c|c|c|c|c|c|c|c|c|c|}
\hline & \multirow[b]{2}{*}{$\mathrm{N}$} & \multicolumn{2}{|l|}{ Pre } & \multicolumn{2}{|l|}{ Post } & \multicolumn{2}{|l|}{6 months } & \multicolumn{2}{|c|}{12 month } & \multirow[b]{2}{*}{$\mathrm{df}$} & \multirow[b]{2}{*}{$\mathrm{F}$} & \multirow[b]{2}{*}{$\mathrm{p}$} \\
\hline & & Mean & SD & Mean & SD & Mean & SD & Mean & SD & & & \\
\hline Weight* & 40 & $\begin{array}{l}92.25 \mathrm{~kg} / \\
203 \mathrm{lbs}\end{array}$ & 18.73 & $\begin{array}{l}91.85 \mathrm{~kg} / \\
202.1 \mathrm{lbs}\end{array}$ & 18.88 & $\begin{array}{l}90.16 \mathrm{~kg} / \\
198.4 \mathrm{lbs}\end{array}$ & 17.71 & $\begin{array}{l}87.20 \mathrm{~kg} / \\
191.8 \mathrm{lbs}\end{array}$ & 18.28 & $\begin{array}{l}{[1.04,40 .} \\
70]\end{array}$ & 9.81 & $* 0.003$ \\
\hline BMI* & 40 & 33.00 & 6.60 & 32.85 & 6.83 & 32.34 & 6.46 & 30.73 & 6.56 & {$[1.04,40.57]$} & 13.73 & $* 0.001$ \\
\hline FCI Total * & 40 & 61.87 & 16.39 & 47.93 & 12.58 & 53.38 & 18.58 & 48.47 & 13.80 & {$[2.78]$} & 24.58 & $*<0.001$ \\
\hline POF Total* & 39 & 71.79 & 19.79 & 52.21 & 18.09 & 49.68 & 19.48 & 46.46 & 18.67 & {$[2.76]$} & 30.74 & $*<0.001$ \\
\hline Restraint Total & 39 & 32.59 & 4.88 & 31.41 & 4.73 & 30.46 & 5.84 & 29.51 & 4.83 & {$[2.76]$} & 8.78 & $*<0.001$ \\
\hline SA45GSI & 45 & 59.20 & 9.80 & 56.24 & 7.70 & 53.02 & 10.03 & 53.73 & 9.60 & [2.88] & 8.94 & $*<0.001$ \\
\hline SA45PST * & 45 & 58.56 & 9.54 & 56.09 & 8.34 & 53.66 & 10.65 & 53.93 & 10.52 & [2.88] & 5.88 & $* 0.004$ \\
\hline
\end{tabular}

Note: ${ }^{*} \mathrm{p}<.0 .05$ Abbreviations: BMI-Body Mass Index; FCI-Food Craving Inventory; POF-Power of Food Scale; Restraint-Revised Restraint Scale; SA45GSI-Symptom Assessment Global Severity Index; SA45PST-Symptom Assessment Positive Symptom Index

All participants chose one food to address in their treatment group and the following frequencies were reported: chocolate $(\mathrm{N}=53,60 \%)$, salty foods (e.g. chips, crisps, salted nuts; $\mathrm{N}=10,11 \%$ ), sweet carbohydrate foods (e.g., cakes, biscuits, soft/soda drinks; $\mathrm{N}=13,14.5 \%$ ), carbohydrate foods which are neither sweet nor salty such as white refined foods (e.g., bread, rice, pasta; $\mathrm{N}=13$, $14.5 \%)$ and caffeinated products $(\mathrm{N}=0)$.

Fifty-eight participants indicated they were consuming their craved food every day or more $(66 \%)$; 26 were consuming the food two to six times per week $(29 \%)$ and five participants were consuming it once per week $(5 \%)$.

\subsection{Quantitative Results}

The quantitative results of this trial have been reported elsewhere (Stapleton et al., 2011; 2012a; 2012b; 2013), but are summarised here. EFT, when compared to WL, was found to have an immediate effect on reducing food cravings and at 6- and 12month follow-up (Table 1).

Across the complete group (EFT $+\mathrm{WL}$ who then received treatment), there was a significant reduction from pre-EFT treatment to immediately post-EFT treatment for FCI total scores (mean difference -16.00, $\mathrm{p}<0.001$ ) and this was maintained at 6-months (mean difference $-10.17, \mathrm{p}<0.05)$. There was a significant reduction from pre-treatment to immediately posttreatment for the POF scale (mean difference -23.20, $\mathrm{p}<0.001)$ and this reduction was maintained at the 6month follow up (mean difference $-27.24, \mathrm{p}<0.001$ ). The mean difference for the restraint scale was not significant immediately post-treatment (mean difference -1.71, $\mathrm{p}<0.05)$ but reached significance at the 6 -month point (mean difference -3.46 from pre-treatment, $\mathrm{p}<0.01$ ). There was a further reduction in the restraint score (mean difference $-1.76, p=0.028$ ) between post-treatment and 6-month follow-up indicating that participants were approaching a more 'normal' internal regulation of food intake. For the psychological distress scores, there was a significant reduction in distress from pre- to posttreatment (SA45GSI mean difference $-3.44, \mathrm{p}<0.05$; SA45PST mean difference $-3.56, \mathrm{p}<0.01$ ), indicating that participants were experiencing a reduction in psychological distress immediately following treatment. Both the SA-45 GSI and PST scores were significantly reduced at 6 months compared to pre-treatment $(\mathrm{p}<0.05)$.

There was also a significant difference pre- to postto 12-month in all measures including participants' weight, BMI, FCI total, POF total, Revised Restraint, SA45GSI and SA45PST $(\mathrm{p}<0.05) \quad$ indicating participants demonstrated a significant change across these measures over time. There were significant reductions from pre-treatment to 12-months for participants' weight (mean difference $-5.05 \mathrm{~kg}$ or $11.1 \mathrm{lbs}, \mathrm{p}<0.05$ ), BMI (mean difference $-2.28, \mathrm{p}<0.05$ ), FCI total scores (mean difference $-13.40, \mathrm{p}<0.001$ ), POF total score (mean difference -25.33, $\mathrm{p}<0.001$ ), Restraint (mean difference -3.08, $\mathrm{p}<0.001$ ) and SA45GSI (mean difference 5.47, $\mathrm{p}<0.05$ ). There was no significant difference for SA45PST pre-treatment to 12months (mean difference $-4.62, \mathrm{p}<0.05$ ).

Post-treatment versus 12-months, indicated there were significant reductions for participants' weight (mean difference $-4.65 \mathrm{kgs} / 10.2 \mathrm{lbs}, \mathrm{p}<0.05$ ) and BMI (mean difference $-2.13, \mathrm{p}<0.05$ ). There was no significant difference for FCI total scores, POF total score, Restraint, SA45GSI and SA45PST scores from post-treatment to 12 months. However, it is worth noting that the significant reductions in these measures achieved from pre- to post-treatment were maintained at the 6month point (with the exception of Restraint which reached significance at 6-months; Table 1). 
Table 2. Frequency of Themes Recorded in 7- and 14-Day Intervals

\begin{tabular}{|c|c|c|c|c|c|c|}
\hline & \multicolumn{3}{|c|}{ 7-Day } & \multicolumn{3}{|c|}{ 14-Day } \\
\hline & $\mathrm{N}$ & Frequency & $\%$ & $\mathrm{~N}$ & Frequency & $\%$ \\
\hline Physiological & 89 & 0 & 0.0 & 81 & 5 & 5.6 \\
\hline Enjoyment/Celebration & 89 & 7 & 7.7 & 81 & 6 & 6.6 \\
\hline Missing Out & 89 & 6 & 6.6 & 81 & 7 & 7.7 \\
\hline Reward & 89 & 19 & 19.4 & 81 & 18 & 20.5 \\
\hline Wastage & 89 & 34 & 38.3 & 81 & 24 & 27.0 \\
\hline Emotive & 89 & 20 & 22.4 & 81 & 16 & 18.0 \\
\hline External Environment & 89 & 0 & 0.0 & 81 & 0 & 0.0 \\
\hline
\end{tabular}

Table 3. Frequency of Cravings and SUDS Recorded in 7- and 14-Day Intervals

\begin{tabular}{|c|c|c|c|}
\hline \multicolumn{2}{|l|}{ 7-Day } & \multicolumn{2}{|l|}{ 14-Day } \\
\hline Cravings & Frequency & Cravings & Frequency \\
\hline 1 & 20 & 1 & 20 \\
\hline 2 & 26 & 2 & 18 \\
\hline 3 & 18 & 3 & 12 \\
\hline 4 & 7 & 4 & 9 \\
\hline 5 & 4 & 5 & 1 \\
\hline 6 & 2 & 6 & 1 \\
\hline 7 & 0 & 7 & 1 \\
\hline 8 & 1 & 8 & 0 \\
\hline SUDS & & SUDS & \\
\hline Less than 5 & $42(47 \%)$ & Less than 5 & $49(60 \%)$ \\
\hline More than 5 & $47(53 \%)$ & More than 5 & $32(40 \%)$ \\
\hline
\end{tabular}

\subsection{Food Diaries}

The solicited participant diaries were a useful strategy for rich data collection. Table 2 outlines the themes identified and frequency of recordings in 7- and 14-day intervals. The most common themes recorded included Wastage, Emotive and Reward.

Table 3 indicates the frequency of cravings and SUD scale (Wolpe, 1990) ratings recorded in 7- and 14-day intervals. The most frequent number of cravings recorded ranged from one to three and more than $50 \%$ of participants indicated SUDS ratings higher than 5 out of 10 across a 7 -day period and $40 \%$ higher than a five across a 12-day period.

\section{DISCUSSION}

Across both the 7- and 14-day analyses, the majority of cravings were occurring between one and three times per day and more than $50 \%$ of participants indicated SUDS ratings higher than 5 out of 10 across a 7-day period and $40 \%$ higher than a five across a 12-day period. These women were clearly struggling with frequency and intensity of cravings.
The most common themes recorded throughout participants' diaries indicating why they were eating included Wastage, Emotive and Reward and the most commonly chosen food to address these was chocolate $(60 \%)$. Eating sweet foods has previously been shown to provide alleviation from stress in vulnerable people via enhanced function of the serotonergic system (Gibson, 2006). Eating food because of Wastage (any reason for eating related to concern for discarding food) was the strongest reason cited and is of particular interest given the majority of women in the study were aged 41-56+ years. We noted anecdotally while conducting the treatment groups, that these women had great difficulty with discarding food once they have dealt with the craving issue through the EFT procedure. Even though they openly reported they did not want to eat the craved food anymore as it had lost its appeal, they most definitely did NOT want to throw the food out. What emerged were the long held beliefs and emotions about 'wasting food', which they had mostly learnt from their mothers and grandmothers. Historically, these predecessors were women, who grew up in the Great Depression era of the $1920 \mathrm{~s}$ and World Wars (I and II), 
where food may have been scarce, famine was very common and to waste food would have been unheard of. The concern over waste theme in the studied food diaries has confirmed these clinical observations.

Diary entries, which highlight these themes, include the following:

Daughter and I made scones to eat because has cream in fridge. Great to cook with her but thinking I should have just thrown the cream out rather than make and buy things to have with it (bought strawberries too). Realised definitely having cream in house makes it so I can't think of having any other food, but I just can't throw food out. (Female, aged 40 years).

Babysat grandchild and she ate lollies. I had 3. Feeling like a naughty child. She wanted some cake at café and I ate the leftovers. (Female aged 59 years).

The field of Epigenetics, which means 'above genetics', (Bird, 2007; Holliday, 2006) is now suggesting that the effects of a grandparents' lifestyle or grandmother's diet, could have been passed down, not through their genes, but through something beyond their genes. The effects of maternal nutrition or other environmental 'exposures' are well recognized, therefore in the nutritional field, epigenetics is exceptionally important because food intake can modify epigenetic phenomena and alter the expression of genes (Whitelaw, 2006). Based on this knowledge, it was no surprise that the women in the treatment groups had ingrained reactions towards going without food, wasting food and even hoarding it 'just in case'. This may have been very relevant to their ancestors, but not so much in the current food-abundant lifestyle of today.

Firstly, environments that are nutritionally limited (e.g., during the Great Depression in the 1920s) may mismatch individuals later in life when food-dense environments are now available (Gluckman and Hanson, 2008). A woman pregnant after the two World Wars, who may have grown up in a time of famine and then exposed her child to an early life of food scarcity, may have altered epigenetic mechanisms involved in the obesity susceptibility in the child (Martinez et al., 2012).

A second possible pathway is that foetal or infant over nutrition resulting in adult obesity (e.g., a woman who lives through World War II and has a child after the war compensates for her own under nutrition by overfeeding her child). That child would now be over 50 years of age and living in a very energy-dense environment (Gluckman and Hanson, 2008). What is clear is that the maternal nutritional environment induces the expression of genes and involves the altered epigenetic regulation of specific genes (Lillycrop and Burdge, 2010) and the age range in the present study indicated these women grew up with mothers and grandmothers from the early part of the century.

Eating a food in response to a strong emotion has been noted (Gibson, 2006) and also featured as one of the main themes identified in the present study. Mood and emotion may influence food choice via hedonic and physiological effects that change appetite (e.g., sweet foods such as chocolate), or mood modification may be an outcome of conscious or unconscious food choice (Gibson, 2006). Previous research has also identified that cravings and consumption are often associated with negative moods such as boredom, anger and tiredness (Rogers and Smit, 2000). Psychological factors, stress and underlying personal issue's can lead to a lack of energy and motivation and increased food consumption (e.g., emotional or comfort eating), which may indirectly contribute to weight gain (NHMRC, 2013). There is a strong association between mood disorders and obesity; people with obesity are more likely to become depressed over time and people with depression are more likely to become obese. Obesity may increase risk factors for mood states such as depression (e.g., body dissatisfaction and low self-esteem) and in turn, depression and poor body image can affect people's ability and willingness to eat healthily and exercise (NHMRC, 2013).

Diary entries highlighting this theme include:

Feeling low, easily irritated, having trouble motivating self and with focus. Have many jobs to be done before I can do what I want to do. Would love to go out for coffee and food, just some indulgent food that would make me feel sated. I have this primitive feeling that if I have a big satisfying feed for my hunger, my obsessions, cravings, will go away. (Female, aged 43 years).

Angry about sugar craving. Driving car home. Should have had lunch. Been a bad week, depressed. (indicated ate chocolate and biscuits in car; Female, aged 52 years).

The third theme which emerged, eating a craved food as a reward for oneself, is also prominent in the literature. It has been proposed that obese individuals tend to experience greater activation of the meso-limbic 
reward system in response to food intake (reward), which may increase the risk for overeating (Davis et al., 2004). However, more recent research has suggested that obese individuals experience less activation of the mesolimbic reward system in response to food intake, which leads them to overeat to compensate for this deficiency (Comings and Blum, 2000; Volkow et al., 2002). It may also be that anticipating a rewarding feeling from eating the craved food itself reinforces the behavior (Pelchat et al., 2004; Roefs et al., 2005).

Participants indicated this theme through the following diary entries:

Out shopping with friend and kids. Everyone having KFC (fried chicken). Tried to talk myself out of it but made lots of excuses and gave in. Think I am just rebelling. Have done so well lately. Needed to acknowledge that. (Female, aged 32 years)

Driving home. Saw McDonalds (fast food) and wanted a treat. (Female, aged 43 years)

Although the present food diary findings confirm quantitative research, some limitations remain. First, it has to be noted that the sample size was relatively small $(\mathrm{N}=89)$ and only consisted of women. However, gender-specific differences do occur between men and women, in regards to nutrient intake, food consumption, binge-eating and restrained eating (e.g., women are less satisfied with their weight, engage in more restrained eating and dieting and suffer more eating disorders, including emotional eating and food cravings (Kiefer et al., 2005). Future designs would benefit from including males as well as females. The very act of keeping food diaries may have induced some people to alter their behavior and, although participants were requested to complete the diaries in real time, they may have done so retrospectively resulting in memory biases or deficiencies. Using electronic rather than paper diaries (e.g. preprogrammed applications on smart phones to remind participants to complete the diary every meal time) may be a more suitable substitute in future studies.

Nevertheless, this study of food diaries during a treatment trial in overweight and obese adults highlight the importance of addressing the issue of food wastage as well as eating in response to emotion or as a reward in weight-loss treatment programs. It is known that food cravings play a role in maintaining excessive eating patterns observed in binge-eating, bulimia nervosa and obesity, but few treatment programs to date address the epigenetic contribution of previous generations in the consumption of craved foods.

\section{CONCLUSION}

The use of diary analysis as a qualitative tool has value as a social research method and has the potential to facilitate the study of food craving processes and reveal the reasons associated with craving consumption in overweight adults.

\section{ACKNOWLEDGMENT}

Many thanks to Terri Sheldon and Brett Porter for their review of this paper.

\section{REFERENCES}

ABS, 2012. Australian health survey: First results. Australian Institute of Health and Welfare. Canberra.

Bandura, A., 1986. The explanatory and predictive scope of self-efficacy theory. J. Soc. Clin. Psychol., 4: 359-373. DOI:10.1521/jscp.1986.4.3.359

Baumeister, R.F. and K.D. Vohs, 2003. Willpower, Choice and Self-Control. In: Time and Decision: Economic and Psychological Perspectives on Intertemporal Choice, Loewenstein, G., D. Read and R.F. Baumeister (Eds.), Russell Sage Foundation, New York, ISBN-10: 0871545497, pp: 201-216.

Bird, A., 2007. Perceptions of epigenetics. Nature, 447: 396-398. DOI: 10.1038/nature05913

Cereda, E., A.E. Malavazos, R. Caccialanza, M. Rondanelli and G. Fatati et al., 2011. Weight cycling is associated with body weight excess and abdominal fat accumulation: A cross-sectional study. Clin. Nutr., 30: 718-723. DOI: 10.1016/j.clnu.2011.06.009

Church, D., G. Yount and A.J. Brooks, 2012. The effect of emotional freedom techniques on stress biochemistry: A randomized controlled trial. J. Nervous Mental Dis., 200: 891-896. DOI: 10.1097/NMD.0b013e31826b9fc1

Comings, D. E. and K. Blum, 2000. Reward deficiency syndrome: Genetic aspects of behavioral disorders. Progress Brain Res., 126: 325-341. DOI: 10.1016/S0079-6123(00)26022-6

Craig, G., 2011. The EFT Manual. 1st Edn., Elite Books, Santa Rosa, CA., ISBN-10: 1604150661, pp: 276.

Davis, C., S. Strachan and M. Berkson, 2004. Sensitivity to reward: Implications for overeating and overweight. Appetite, 42: 131-138. DOI: 10.1016/j.appet.2003.07.004 
Dey, I., 1993. Qualitative Data Analysis: A User Friendly Guide for Social Scientists. 1st Edn., Routledge, USA., ISBN-10: 041505852X, pp: 304.

Feinstein, D., 2012. Acupoint stimulation in treating psychological disorders: Evidence of efficacy. Rev. General Psychol., 16: 364-380. DOI: 10.1037/a0028602

Fitzpatrick, R. and M. Boulton, 1994. Qualitative methods for assessing health care. Q. Health Care, 3: 107-113. DOI: 10.1136/qshc.3.2.107

Flint, G.A., W. Lammers and D.G. Mitnick, 2005. Emotional freedom techniques. J. Aggression, Maltreatment Trauma, 12: 125-150. DOI: 10.1300/J146v12n01_07

Foster, G.D., D.B. Sarwer and T.A. Wadden, 2012. Psychological effects of weight cycling in obese persons: A review and research agenda. Obesity Res., 5: 474-488. DOI: 10.1002/j.15508528.1997.tb00674.x

Fujioka, K., 2012. Management of obesity as a chronic disease: Nonpharmacologic, pharmacologic and surgical options. Obesity Res., 10: 116S-123S. DOI: 10.1002/j.1550-8528.1997.tb00674.x

Gibson, E.L., 2006. Emotional influences on food choice: Sensory, physiological and psychological pathways. Physiol. Behav., 89: 53-61. DOI: 10.1016/j.physbeh.2006.01.024

Gluckman, P. and M. Hanson, 2008. Developmental and epigenetic pathways to obesity: An evolutionarydevelopmental perspective. Int. J. Obesity, 32: S62S71. DOI: 10.1038/ijo.2008.240

Grant, P.G., J. Buckroyd and S. Rother, 2008. Food for the Soul: Social and Emotional Origins of Comfort Eating in the Morbidly Obese. In: Psychological Responses to Eating Disorders and Obesity: Recent and Innovative Work, Buckroyd, J. and S. Rother (Eds.), John Wiley and Sons, Chichester, ISBN-10: 0470061642, pp: 103-119.

Herman, C.P. and J. Polivy, 1980. Restrained eating. Obesity, 208-225. DOI: 10.1037/0021-843X.97.3.354

Hill, J.O., H. Wyatt, S. Phelan and R. Wing, 2005. The national weight control registry: Is it useful in helping deal with our obesity epidemic? J. Nutr. Educ. Behav., 37: 206-210. DOI: 10.4236/health.2012.48079

Holliday, R., 2006. Epigenetics: A historical overview. Epigenetics, 1: 76-80. PMID: 17998809

Hollis, J.F., C.M. Gullion, V.J. Stevens, D.P. Brantley and J. Appel et al., 2008. Weight loss during the intensive intervention phase of the weight-loss maintenance trial. Am. J. Preventive Med., 35: 118126. DOI: 10.1016/j.amepre.2008.04.013
James, P.T., R. Leach, E. Kalamara and M. Shayeghi, 2012. The worldwide obesity epidemic. Obesity Res., 9: 228S-233S. DOI: 10.1038/oby.2001.123

Kiefer, I., T. Rathmanner and M. Kunze, 2005. Eating and dieting differences in men and women. J. Men's Health Gender, 2: 194-201. DOI: 10.1016/j.jmhg.2005.04.010

LE, 2011. The Herald/Age-Lateral Economics Index of Australia's Wellbeing. Australia.

Lillycrop, K.A. and G.C. Burdge, 2010. Epigenetic changes in early life and future risk of obesity. Int. J. Obesity, 35: 72-83. DOI:10.1038/ijo.2010.122

Lowe, M.R., M.L. Butryn, E.R. Didie, R.A. Annunziato and J.G. Thomas et al., 2009. The power of food scale. A new measure of the psychological influence of the food environment. Appetite, 53: 114-118. DOI: 10.1016/j.appet.2009.05.016

Mann, T., A.J. Tomiyama, E. Westling, A.M. Lew and B. Samuels et al., 2007. Medicare's search for effective obesity treatments: Diets are not the answer. Am. Psychol., 62: 220. DOI: 10.1037/0003-066X.62.3.220

Martinez, J.A., P. Cordero, J. Campion and F.I. Milagro, 2012. Interplay of early-life nutritional programming on obesity, inflammation and epigenetic outcomes. Proc. Nutr. Soc., 71: 276-283. DOI: $10.1017 / \mathrm{S} 0029665112000055$

McGuire, M.T., R.R. Wing, M.L. Klem and J.O. Hillf, 1999. Behavioral strategies of individuals who have maintained long-term weight losses. Obesity Res., 7: 334-341. PMID: 10440589

Miles, M.B. and A.M. Huberman, 1984. Qualitative Data Analysis: A Sourcebook of New Methods. 1st Edn., SAGE Publications Inc., California, ISBN-10: 0803922744, pp: 256.

NHMRC, 2013. Clinical Practice Guidelines for the Management of Overweight and Obesity in Adults, Adolescents and Children in Australia. Department of Health and Ageing, Australia.

Pelchat, M.L., A. Johnson, R. Chan, J. Valdez and J.D. Ragland, 2004. Images of desire: Food-craving activation during fMRI. Neuroimage, 23: 14861493. DOI: 10.1016/j.neuroimage.2004.08.023

Perri, M. and P. Fuller, 1995. Success and failure in the treatment of obesity: Where do we go from here. Med. Exerc. Nutr. Health, 4: 255-272.

Perri, M.G., A.M. Nezu, E.T. Patti and K.L. McCann, 1989. Effect of length of treatment on weight loss. J. Consulting Clinical Psychol., 57: 450. DOI: 10.1037/0022-006X.57.3.450

Polivy, J., Herman, C.P. and K.I. Howard, 1988. The restraint scale: Assessment of dieting. Dictionary Behav. Assess. Techn., 377-380. DOI: 10.1002/food.19890330140 
Prochaska, J.O., C.C. DiClemente and J.C. Norcross, 1992. In search of how people change: Applications to addictive behaviors. Am. Psychol., 47: 11021114. DOI: 10.1037/0003-066X.47.9.1102

Raynor, H.A., R.W. Jeffery, S. Phelan, J.O. Hill and R.R. Wing, 2012. Amount of food group variety consumed in the diet and long-term weight loss maintenance. Obesity Res., 13: 883-890. DOI: 10.1038/oby.2005.102

Roefs, A., C. Herman, C. MacLeod, F. Smulders and A. Jansen, 2005. At first sight: How do restrained eaters evaluate high-fat palatable foods? Appetite, 44: 103-114. DOI: 10.1016/j.appet.2004.08.001

Rogers, P.J. and H.J. Smit, 2000. Food craving and food "addiction": A critical review of the evidence from a biopsychosocial perspective. Pharmacol. Biochem. Behav., 66: 3-14. DOI: 10.1016/S00913057(00)00197-0

RWHOC, 2000. Obesity: Preventing and managing the global epidemic. World Health Organ. Tech. Rep. Ser. PMID: 11234459

SAI, 1998. Symptom Assessment-45 Questionnaire (SA45): Technical Manual. 1st Edn., Multi-Health Systems Inc., North Tonawanda, New York, pp: 113.

Sechrist, G.B., C. Stangor, K. Brownell, R. Puhl and M. Schwartz et al., 2005. Social Consensus and the Origins of Stigma. In: Weight Bias: Nature, Consequences and Remedies, Brownell, K.D., R.M. Puhl, M.B. Schwartz and L. Rudd (Eds.), Guilford Publications, USA., ISBN-10: 1593851995, pp: 97108.

Shaw, K., P. O'Rourke, C. Del Mar and J. Kenardy, 2005. Psychological interventions for overweight or obesity. Cochrane Database Syst. Rev., 2. DOI: 10.1002/14651858.CD003818.pub2

Stapleton, P., D. Church, T. Sheldon, B. Porter and C. Carlopio, 2013. Depression symptoms improve after successful weight loss with emotional freedom techniques. A randomized controlled trial. ISRN Psychiatry. DOI: 10.1155/2013/573532

Stapleton, P., T. Sheldon and B. Porter, 2012a. Clinical benefits of emotional freedom techniques on food cravings at 12-months follow-up: A randomised controlled trial. Energy Psychol. J., 4: 1-11.

Stapleton, P., T. Sheldon and B. Porter, 2012b. Practical Application of emotional freedom techniques for food cravings. Int. J. Heal. Car., 12: 1-9.

Stapleton, P., T. Sheldon, B. Porter and J. Whitty, 2011. A randomised clinical trial of a meridian-based intervention for food cravings with six-month follow-up. Behav. Change, 28: 1-16. DOI: 10.1375/bech.28.1.1
Teachman, B.A., R.K. Mallett, K. Brownell, R. Puhl and M. Schwartz et al., 2005. Measurement of Bias. In: Weight Bias: Nature, Consequences and Remedies, Brownell, K.D., R.M. Puhl, M.B. Schwartz and L. Rudd (Eds.), Guilford Publications, USA., ISBN-10: 1593851995, pp: 121-133.

Tesch, R., 1990. Qualitative Research Analysis Types and Software Tools. 1st Edn., Routledge, USA., ISBN-10: 1850006091, pp: 344.

Trogdon, J.G., Finkelstein, E.A., T. Hylands, P.S. Dellea and S.J. Kamal-Bahl, 2008. Indirect costs of obesity: A review of the current literature. Obesity Rev., 9: 489-500. DOI: 10.1111/j.1467-789X.2008.00472.x

Volkow, N.D., J.S. Fowler, G.J. Wang and R.Z. Goldstein, 2002. Role of dopamine, the frontal cortex and memory circuits in drug addiction: Insight from imaging studies. Neurobiol. Learn. Memory, 78: 610-624. DOI: 10.1006/nlme.2002.4099

Wadden, T., M. Butryn and K.J. Byrne, 2004. Efficacy of lifestyle modification for long-term weight control. Obesity Res., 12: 151S-162S. DOI: 10.1038/oby.2004.282

Weber, R.P., 1990. Basic Content Analysis. 2nd Edn., Sage Publications, Incorporated, USA., ISBN-10: 0803938632, pp: 96.

White, M.A. and C.M. Grilo, 2005. Psychometric properties of the Food Craving Inventory among obese patients with binge eating disorder. Eat. Behav., 6: 239-246. DOI: 10.1016/j.eatbeh.2005.01.001

White, M.A., B.L. Whisenhunt, D.A. Williamson, F.L. Greenway and R.G. Netemeyer, 2002. Development and validation of the food-craving inventory. Obesity Res., 10: 107-114. DOI: 10.1038/oby.2002.17

Whitelaw, E., 2006. Epigenetics: Sins of the fathers and their fathers. Eur. J. Hum. Genet., 14: 131-132. DOI: 10.1038/sj.ejhg. 5201567

Wing, R.R. and J.O. Hill, 2001. Successful weight loss maintenance. Annual Rev. Nutrition, 21: 323-341. DOI: 10.1146/annurev.nutr.21.1.323

Wing, R.R. and S. Phelan, 2005. Long-term weight loss maintenance. Am. J. Clin. Nutr., 82: 222S-225S.

Wolpe, J., 1990. The Practice of Behavior Therapy. 4th Edn., Pergamon Press, New York, ISBN-10: 0080364551, pp: 421. 